\title{
CLINICAL "ASSAY" OF CORTICOTROPHIN PRELIMINARY COMPARISON OF METHODS
}

\author{
BY
}

\author{
B. M. ANSELL and E. G. L. BYWATERS \\ From the Special Unit for Juvenile Rheumatism, Canadian Red Cross Memorial Hospital, Taplow, Berks
}

(RECEIVED FOR PUBLICATION MAY 1, 1952)

The difficulties in the assay of pituitary corticotrophin are well known. The two accepted methods are based on animal assay and the results are not always congruent. Thus a corticotrophin which has a high potency in the Sayer's test may show a low adrenal weight maintenance factor (Young and Stack-Dunne, 1951; Parkes, 1951). Since corticotrophin is primarily needed for the treatment of human disease we thought it necessary to attempt the evaluation of various corticotrophin batches, using as a criterion the clinical response in patients with responsive diseases.

The batches employed in this study were from Armour and Co. Ltd. (J 28112, J 27511, K 50902, $\mathrm{K}$ 31002, K 50802, K 29901, and K 53103, all supplied by the Ministry of Health) and from Crookes Laboratories Ltd. (EC4).

\section{Methods of Assessment}

For this purpose we selected eight patients who appeared to be in a relatively stable state and had measurable dysfunction. All except one had rheumatoid arthritis. The clinical criteria used for assessment were four in number:

(1) Pain.-This was elicited by firm digital pressure over an affected joint (this was graded 0 to 3, 0 representing no pain, 1 slight pain, 2 wincing, 3 wincing and withdrawal).

(2) Range of Movement of an Involved Joint.-This was obtained from the difference between full flexion and full extension; the latter angles were read on a protractor only when the clamped arms of the jointed rods had been transferred to the table. The three bony points were marked with indian ink to ensure accuracy.

(3) Timing.-The standard test used was the number of seconds taken for the patient to walk $22 \mathrm{yds}$. This was employed in all cases in which joints of the lower limbs were affected.

(4) Maximal Strength of Grip.-This was measured in $\mathrm{mm}$. $\mathrm{Hg}$ by compression of a rubber bag.

All the above measurements were made personally by one of us (B.A.). In all cases the oral temperature was taken twice daily. In one case of acute disseminated lupus erythematosus the presence of a rash and chest signs were also included as criteria of activity.

In spite of the apparent simplicity of all these tests, we found that it was important for the patient to be well-trained as well as stable, since gradual improvement on repetition tended to occur in all tests for a week or so, after which the standard remained at the new level.

In addition, laboratory observations were made on the erythrocyte sedimentation rate (Westergren method), the direct eosinophil count (Randolph method, 1944), and the 24-hr urinary 17-ketosteroid excretion (extraction, Robbie and Gibson, 1943; colorimetry, Callow and others, 1938; correction, Talbot and others, 1942).

\section{Methods of Administration}

Three modes of administration were employed: continuous intramuscular therapy, intermittent intramuscular therapy, and intermittent intravenous therapy.

For continuous therapy, patients were treated for 7 days or multiples of 7 days with corticotrophin administered 6-hourly.

For intermittent therapy we first used a standard dose given 6-hourly during a 3-day period, followed by a 4-day period during which control saline injections were given; this weekly cycle being then repeated as often as necessary. Secondly, in an attempt to get a closer assessment of potency, the effect of a large amount of an unknown batch was compared with different doses of a known batch, using 2-day periods of therapy alternating with 3-day control periods. In all such trials by the intramuscular route, function tests and eosinophil counts were performed daily at the same hour.

In trials carried out by the intravenous route, comparison was made again between equivalent doses of different batches as well as between the effect of a large dose of an unknown and differing dose of the standard. In addition, a control saline infusion was also given. The required dose of corticotrophin was added to $500 \mathrm{ml}$. of one-fifth 
normal saline, and adjusted to run in over a period of 8 hours. Eosinophil counts were made at the commencement of the drip and after 4 and 6 hours. Function tests were performed immediately before and after the drip, and daily between therapy periods which were separated from each other by control periods lasting between 4 and 6 days.

\section{Continuous Therapy}

\section{Results}

Case 1, B.W., male, aged 17, had suffered from disseminated lupus erythematosus for $2 \frac{1}{2}$ years and was known to have responded well to corticotrophin on previous occasions. The indices of improvement used here were oral temperature, presence of rash, and presence of "such chest signs as pleural rub, bronchial breathing, and rales. He was given four different batches of corticotrophin (see Fig. 1). Initially $80 \mathrm{mg}$. J 28112 given over $24 \mathrm{hrs}$ reduced his fever, but $40 \mathrm{mg}$. daily failed to control it, though that dose of $\mathrm{J} 27511$ did so. At the end of 14 days on $\mathbf{J} 27511$, in order to ascertain whether the improvement was due to a spontaneous remission, he was returned to $\mathrm{J} 28112$. The high fever and chest signs recurred and a rash developed on his elbows. All these signs were again controlled by $\mathrm{J}$ 27511. An unknown corticotrophin (C.R.EC4) was then employed, and the dosage modified until a com- plete remission occurred, this was $160 \mathrm{mg}$. daily. $\mathrm{He}$ was again put on to $\mathrm{J} 27511$ while he was still in remission, but at the original dosage this no longer controlled his fever, and the rash recurred. A further batch, K 50902, o. was now given at the same dose, but his fever continued $\overrightarrow{\vec{F}}$ and chest signs recurred. He was once more brought $\stackrel{\rho}{\rightarrow}$ into remission by the use of $\mathrm{J} 27511$ now at double the initial dosage, i.e. $80 \mathrm{mg}$. daily, and this remission was maintained on $80 \mathrm{mg}$. K 50902 daily. Relapse occurred $\frac{\text { के }}{6}$ subsequently when an attempt to reduce dosage was made. $\overparen{\nabla}$

The direct eosinophil count was of no value in assessment as there was a tendency to rise (" escape") during क periods of clinical improvement. The sedimentation $\overrightarrow{0}$ rate remained between 90 and $100 \mathrm{~mm}$. in one hour $\overrightarrow{\vec{J}}$ throughout the whole period.

From the above data, therefore, it appears possible to draw tentative deductions as to the relative potency of the different batches employed. Thus, using J 27511 as standard, we can say that $\mathbf{J} 28112$ is well below $\overrightarrow{\dot{\omega}}$ standard, C.R.EC4 approximately half that of the $\omega$ standard, and K 50902 approximately the same as the $\vec{\omega}$ standard. The drawback was that during this pro- 0 longed treatment, relative resistance developed to the $\supset$ action of the hormone, since by the seventh week the $\overrightarrow{C D}$ initial dosage of $\mathbf{J} 27511$ no longer controlled symptoms, but twice that amount did so.

Case 2, J.F., female, aged 12, had been suffering from $\frac{3}{0}$ Still's disease for 2 years. She received two batches, 은

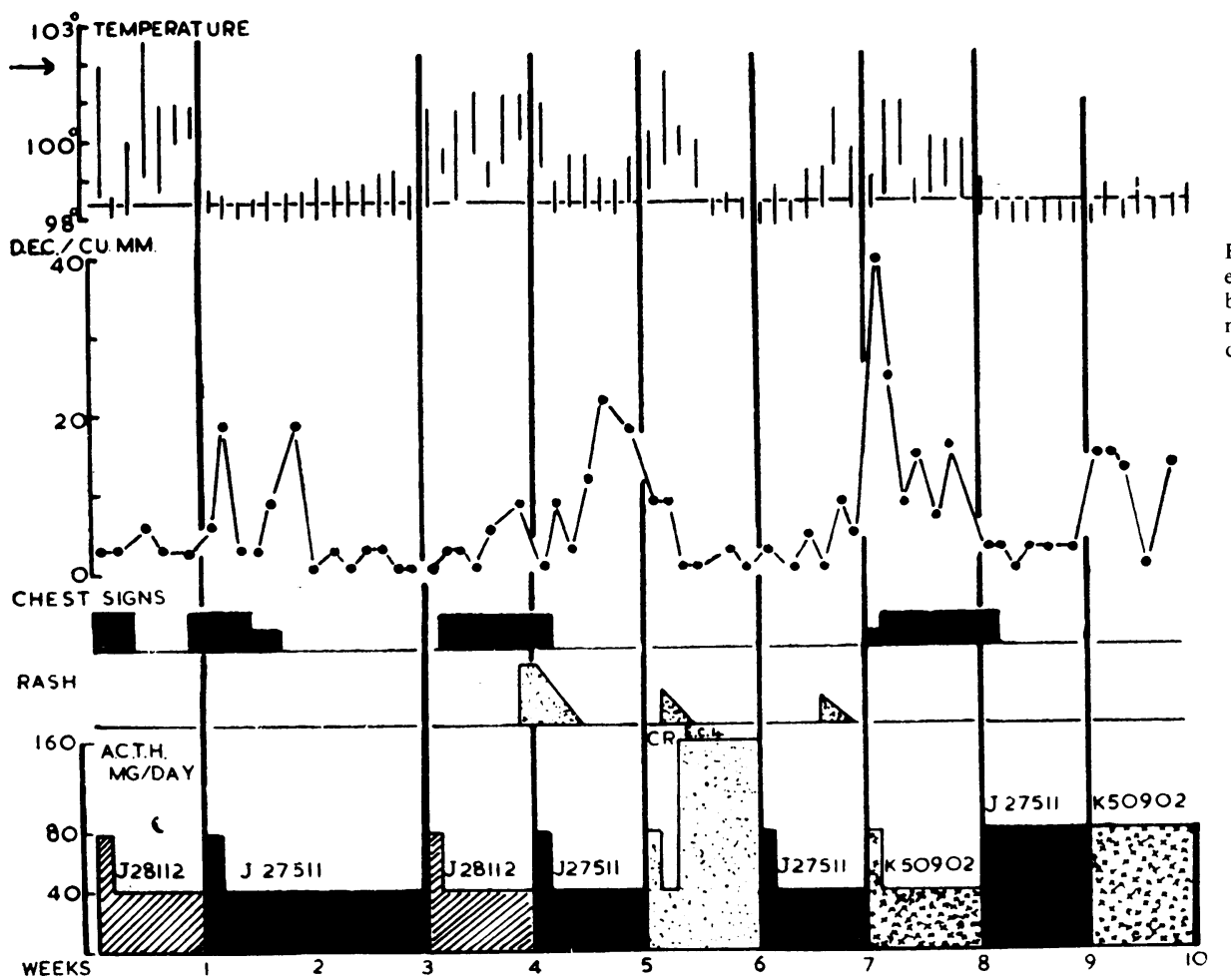

Fig. 1.-Case 1, B.W., effect of corticotrophin batches given intramuscularly four times $\bar{O}$ daily in disseminated lupus erythematosus. 


\section{CLINICAL "ASSAY" OF CORTICOTROPHIN}

K 29901 and K 50902, over three 14-day periods, in dosage decreasing from 80 to $40 \mathrm{mg}$. daily. Over the first fortnight there was a loss of pain associated with some improvement in range of movement of the left elbow and strength of the left grip, together with a fall in sedimentation rate. All this was maintained at the same level in the second and third periods of treatment so that no comparison was possible.

Case 3, R.L., male, aged 15, had had Still's disease for $2 \frac{1}{2}$ years. He received a standard dose of $40 \mathrm{mg}$. daily for 7-day periods and three batches of corticotrophin were used. The first week, K 29901, and the third week, $\mathrm{K} 31002$, were compared with the second and fourth weeks, K 50902. Again it was impossible to judge the effectiveness of individual batches as there was just a gradual improvement throughout in pain, walking time, range of movement, and grip, together with a fall in sedimentation rate. This was particularly marked in the first 2 weeks and was maintained until therapy was discontinued. The eosinophil count was of no real value during therapy but did show a release rise.

Case 4, P.W., female, aged 37, had suffered for 5 years from rheumatoid arthritis affecting most joints but particularly the hands and feet. She was given four 7-day courses of corticotrophin, $40 \mathrm{mg}$. daily intramuscularly, using K 50802, 50902, 31001, and 50902, and then two 7-day courses of $80 \mathrm{mg}$. daily, using K 50902 and 31002. Over the first 3 weeks there was gradual improvement in pain, in times for putting eighty pegs into a board and for walking $22 \mathrm{yds}$, and in grip. These remained fairly constant but with slight fluctuation, suggesting that $\mathrm{K} 31002$ was more potent than 50902, and this was seen both on 40 and on $80 \mathrm{mg}$. daily.

After the first week the eosinophil count fluctuated considerably, reaching as high as 200 , but even so it showed a release rise. The 17-ketosteroid excretion was very low initially, rose rapidly on commencing therapy, and thereafter fluctuated considerably, so that it could not be used as a criterion of assessment. Throughout the period of therapy the sedimentation rate remained at between 70 and $90 \mathrm{~mm}$. in one hour.

A marked feature here was the increased ease with which the patient performed both the function tests and ordinary activities such as sewing, but this was not satisfactorily reflected in either of the timing tests employed.

\section{Intermittent Intramuscular Therapy}

Case 5, D.R., male, aged 9, had had Still's disease for 2 years. He was given a standard dose of $40 \mathrm{mg}$. daily and three batches were employed (Fig. 2). Again we compared the first, J 28112, and the third, K 51303, with the second and the fourth periods, K 50902 .

On J 28112 he showed slight improvement in pain, walking time, range, and grip, all of which deteriorated

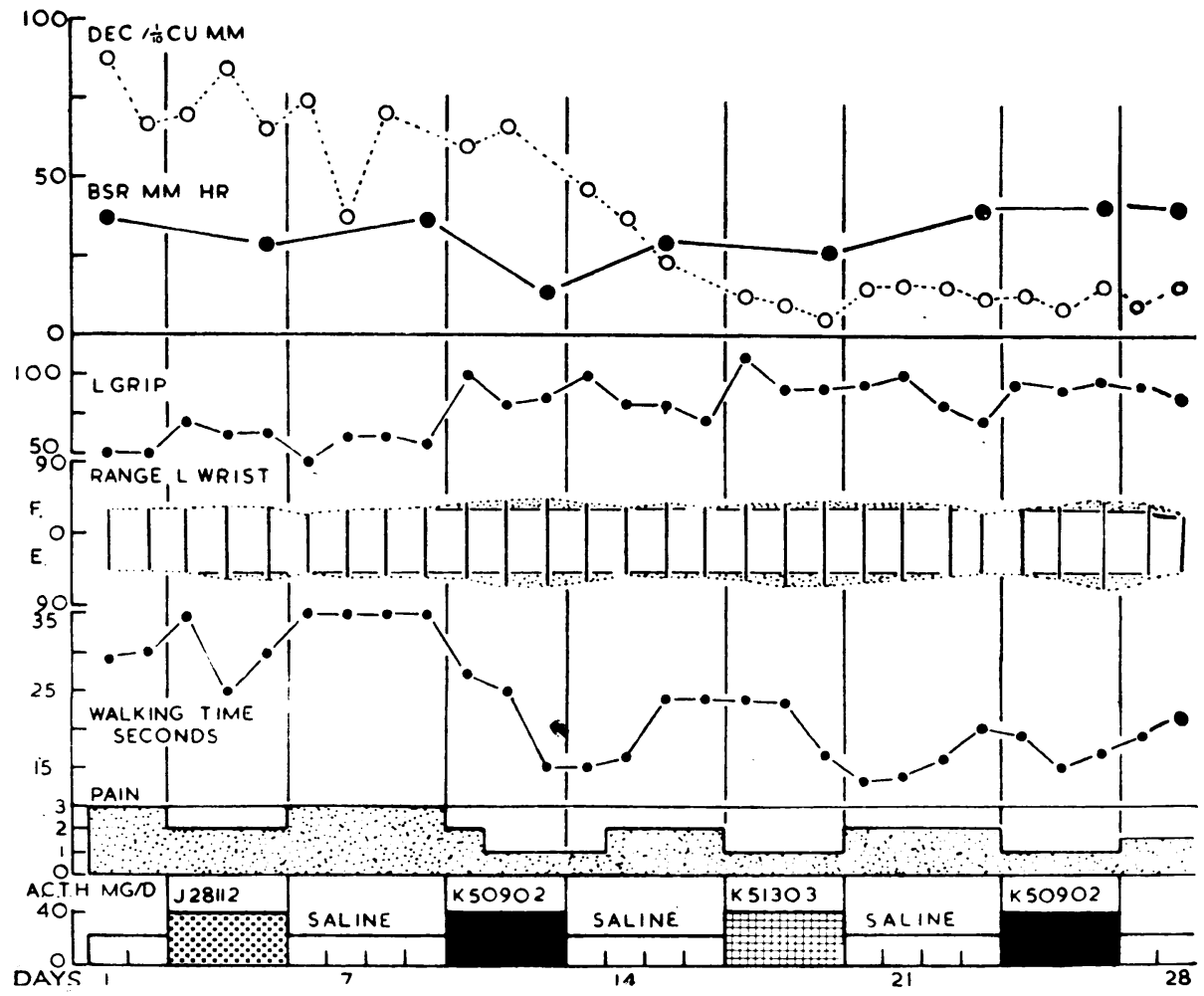

Fig. 2.-Case 5, D.R. comparison of three corticotrophin batches using intermittent intramuscular therapy in Still's disease. 
again in the control period. With K 50902 there was a marked decrease in pain and walking time with increase in range of the left wrist and grip, and relapse when treatment ceased. With K 51303 all criteria showed improvement of an intensity similar to K 50902. Once again the eosinophil count was of no value as it showed a gradual fall throughout the period of observation, while the sedimentation rate fell during the first administration of K 50902, but remained high during the second, despite a similar clinical response.

This method seems superior to the continuous dosage method since it can be seen that $\mathbf{J} 28112$ is considerably inferior in potency to K 50902, while K 51303 is of similar potency. It seems doubtful, however, whether a 4-day control interval is long enough for the effects of the preceding batch to have worn off completely, for on days 16 and 22 (i.e. the days prior to the third and fourth periods of therapy) pain was less and swelling and grip better than at the onset of the trial.

Case 6, I.J., female, aged 9, had had Still's disease for 18 months. In this patient a closer comparison of two batches was attempted. She was first given $100 \mathrm{mg}$. J 28112 daily for 2 days, followed after 3-day intervals by 2-day treatment periods at levels of 25,50 , and $100 \mathrm{mg}$. K 29901 daily. From the response (see Fig. 3) it would appear that the potency of $\mathrm{J} 28112$ was a little over one-quarter and less than one-half of that of $\mathrm{K} 2$ 29901. This method is probably a valuable way of assessing the approximate potency of a corticotrophin $\overline{3}$ which is markedly different from the standard.

The criticism could be made here also that the controlos period was too short, but in this particular instance it is not important, since the answer had already been $\vec{乛}$ obtained before the fourth period (with its larger dosageo and more lasting effects) was undertaken.

\section{Intermittent Intravenous Therapy}

Case 7, R.F., male, aged 15, had been suffering from Still's disease for 18 months. Here equivalent dosage ${ }^{\infty}$ was given intravenously at weekly intervals and the effect $\overrightarrow{0}$ on the eosinophil count and urinary 17-ketosteroid $\overrightarrow{ }$ excretion was compared with the grip and pain reaction $\vec{\omega}$ (Fig. 4). The standard J 27511 was given first and other batches were compared with it. From the clinical and eosinophil response K 29901 and $20 \mathrm{mg}$. C.R.EC4 weresimilar, K 50902 and K 31002 a little inferior, and $\vec{\omega}$ J 28112 considerably inferior to the standard.

The main difficulty here, apart from the local one of $\vec{\omega}$ thrombosis of veins, was the time taken, since by the endo of the fourth week the patient was improving, as shown by an increase in grip and loss of pain during the control $\vec{c}$ period together with a fall in the erythrocyte sedimen-D tation rate, suggesting that he had gone into remission.

The urinary 17-ketosteroids appear to be of little value, $\frac{\mathbb{D}}{3}$ since they show a tendency to rise throughout the whole period with a particularly good response to batch

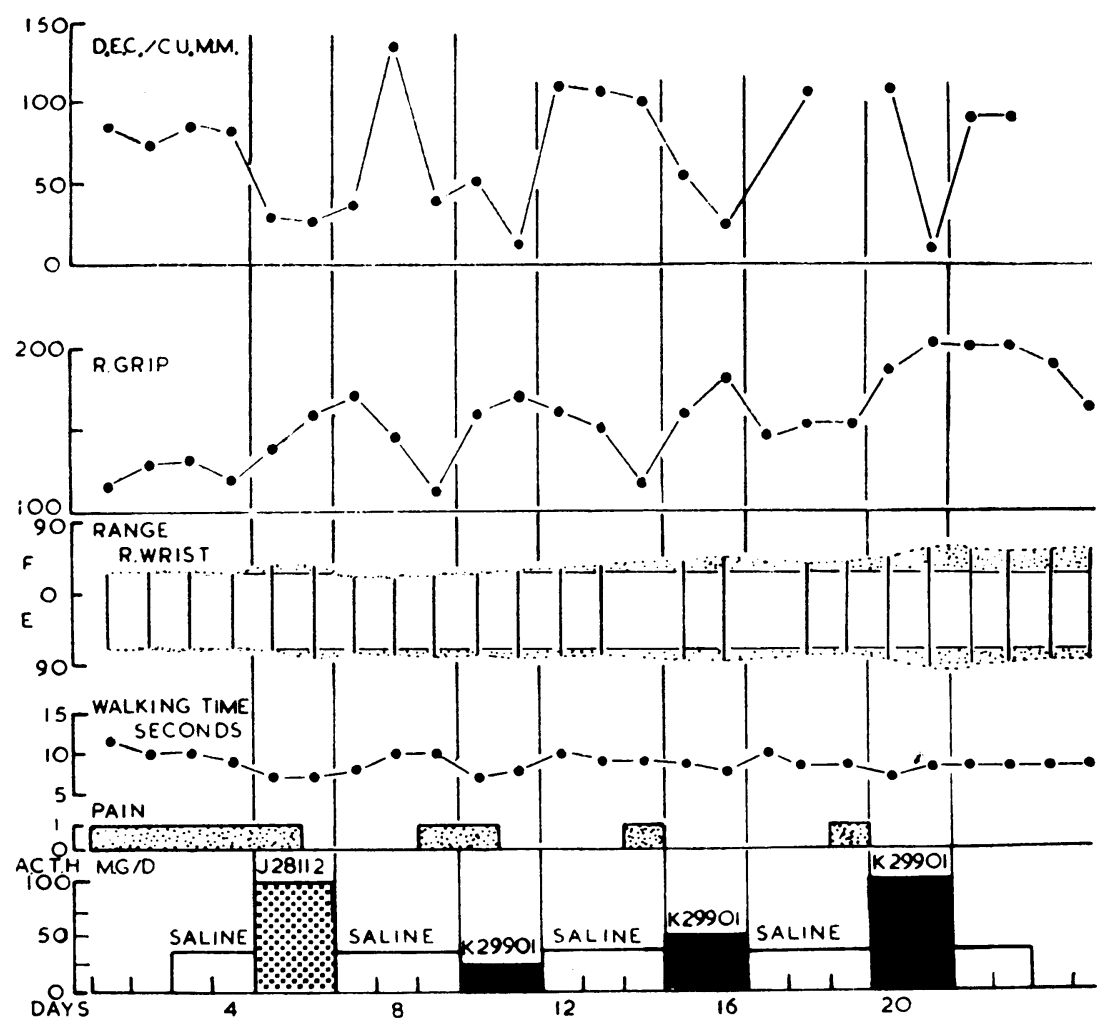

Fig. 3.-Case 6, I.J., comparison of an un-? known corticotrophin batch with different: dosage levels of a@ standard batch given intramuscularly in Still's disease. 
J 28112, which was thought to be much below standard as regards anti-rheumatic effect in these and other patients.

Case 8, I.A., female, aged 11, had had Still's disease for 2 years. The relationship between dose and clinical response was explored, using as standard J 27511 at levels of $2 \cdot 5,5,10$, and $20 \mathrm{mg}$; the response increased with the dose.

The effect of $20 \mathrm{mg}$. J 28112 given 4 days after this series was similar as regards pain and grip to that of $5 \mathrm{mg}$. J 27511. Thus, again, J 28112 appeared to have only one-quarter of the potency of the standard. By the time it was employed, however, the patient had a higher functional state than initially as regards grip and range; it might therefore have been more informative had we employed the unknown first.

The eosinophil count had fallen on each occasion by the 6 th hour, but, since the initial level was very low and fell to 0 even on $2.5 \mathrm{mg}$., it was not considered to be very valuable as a guide to potency.

\section{Discussion}

Continuous intramuscular dosage was of little value for the assessment of potency except in Case 1. Here, however, we were aiming at relieving three signs and the dosage was modified until this was achieved. It would seem that this is a possible method of assay, but in this particular case the development of resistance prevented anything more than a rough idea of relative potency. In the other cases, when making comparisons with a standard batch, continuous therapy was useless, and for this purpose intermittent intramuscular dosage would appear better. The optimum duration both of therapy and of control periods was difficult to determine: 3 days therapy is certainly, and 2 days probably, adequate for a measurable response. The control period of 3 or 4 days could, with advantage, be lengthened with a greater probability of restoration to the basal equilibrium level.

Intravenous therapy certainly gave an excellent clinical response, but again after marked improvement 4 days' rest seemed barely adequate for restoration to the basal level. The saving of time and material with intravenous dosage is balanced by the difficulty with thrombosis of veins, and the theoretical risk of protein shock. The latter does not seem, either from published accounts or from our own experience, to be a practical difficulty. Dosage must be sufficient to cause a measurable improvement, but if too large small differences in potency are missed. On the whole we found that $40 \mathrm{mg}$. of the standard intramuscularly and $10 \mathrm{mg}$.

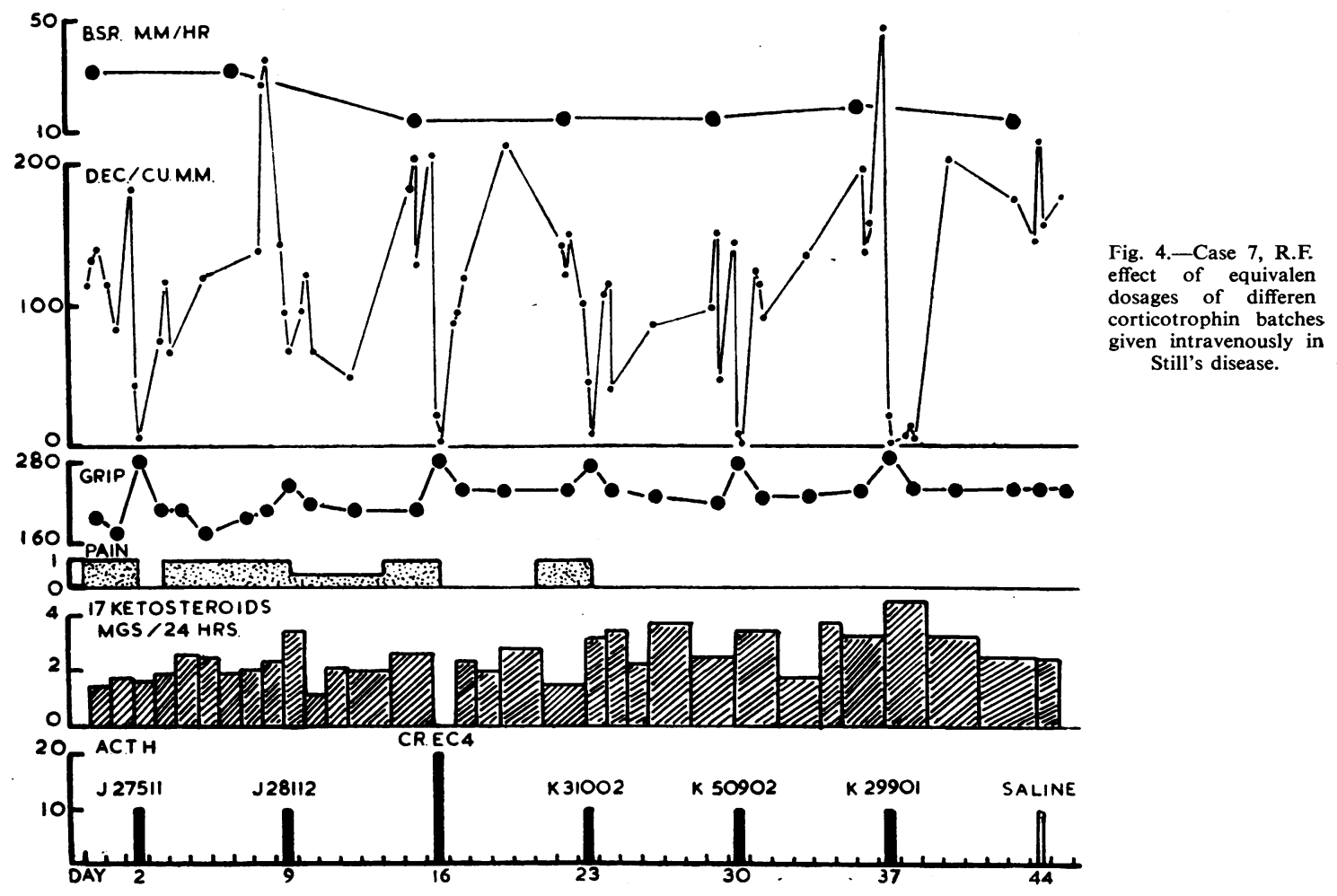

Fig. 4.-Case 7, R.F. of equivalen corticotrophin batches en intravenously in Still's disease. 
intravenously daily gave reasonable results. However, there is considerable individual variation in response to a standard dose. When a batch of corticotrophin has been shown to differ markedly from the standard in potency, comparison of the effect of one dose of this with that of different doses of a standard (as in Cases 6 and 8) would appear a valuable means of assessment. By these methods the following rating of the batches was possible:

RATING OF VARIOUS BATCHES OF CORTICOTROPHIN

\begin{tabular}{c|c}
\hline Rating & Batch \\
\hline \multirow{3}{*}{ Good } & J 27511 \\
\hline & K 29901 \\
\hline & C.R.EC4 \\
\hline Fairly Good & K 50902 \\
\hline & K 31002 \\
\hline Poor & K 51303 \\
\hline
\end{tabular}

Whatever method was employed, one difficulty constantly recurred, that the patient and his disease do not remain the same, sometimes because of development of resistance, and sometimes because of improvement.

However, the more commonly cited criteria of bedside action (the eosinopenic response and the increased excretion of 17-ketosteroids) did not reflect adequately the anti-rheumatic activity of these batches, whichever way the preparations were tested, and we conclude that although the functional assay of corticotrophin is crude, time-consuming, and subject to many variables, it will ultimately provide a more practical basis for assessment than any of the laboratory or animal tests already developed.

\section{Summary}

Methods of assay of corticotrophin for antirheumatic activity, using clinical criteria, have been explored in eight patients. The criteria included pain, movement, a timing test, and a strength test; they were relatively crude and tedious but allowed certain deductions to be made regarding the potency of various batches, such as that "Batch $A$ is about one-quarter the potency of Batch B ".

Three methods have been tested, continuous intramuscular, intermittent intramuscular, and intermittent intravenous using an 8 -hr drip. The last method is probably the best. It should be followed by an interval of at least 4 days or more to allow base line equilibrium to be reached, using a dosage of $10 \mathrm{mg}$. of the Armour standard. It should be preceded by a period of training in the various tests used and should be checked against the effects ot? a control injection of saline.

We wish to thank Miss D. Harding for the eosinophi透 counts, Miss M. N. Powell for estimating the urinary 17-ketosteroids, Mr. P. J. Fiske for photographin the charts, and all members of the Special Unit for theip practical help in the management of the cases.

\section{REFERENCES}

Callow, N. H., Callow, R. K. and Emmens, C. W. (1938). Biochem., 32, 1312 .

Parkes, A. S. (1951). Brit. med. J., 1, 1387.

Randolph, T. G. (1944). J. Allergy, 15, 89.

Robbie, W. A and Gibson, R. B. (1943). J clin Endocr 3,200 으 Talbot, N. B., Berman, R. A. and MacLachlan, E. A. (1942). J. bio $L_{\text {L }}$

Young, F. G. and Stack-Dunne, M. (1951). Brit. med. J., 1, 1386 iv

" Etalonnage" clinique de la corticotrophine Comparaison préliminaire de méthodes

\section{RÉSUMÉ}

On a étudié des méthodes d'étalonnage de la cortico $\triangle$ trophine en ce qui concerne son activité antirhumatismale chez huit malades. On a adopté pour cela des critèreş cliniques, tels que douleur, mouvement, test chronométrique, et test de force. Cette étude, bien que fastidieuse et un peu primitive, a permis toutefois de jugerle pouvoir de différents lots, et on a pu dire, par exempes que "le lot $\mathrm{A}$ est à peu près quatre fois moins fur que le lot B".

On a vérifié trois méthodes: intramusculaire inter mittente, intramusculaire continue, et intraveineuses intermittente goutte à goutte pendant 8 heures. Cetteô dernière méthode semble la meilleure. Elle devrai être suivie d'un intervalle de 4 jours ou plus, pourচ pouvoir atteindre l'équilibre de base, en employant un dosage de $10 \mathrm{mg}$. du standard Armour. Avant d'y $\overrightarrow{\vec{O}}$ procéder il conviendrait d'accoutumer les malades à 3 l'emploi de différents tests, et de vérifier les résultats par rapport à ceux obtenus avec des injections d'eau physio= logique.

\section{Avaluación .clínica de la corticotrofina Comparación preliminar de métodos SUMARIO}

Métodos para avaluar la actividad antireumática de la corticotrofina fueron estudiados en ocho enfermos, sirviéndose de índices clínicos, como dolor, movimiento,음 test cronométrico, y test de fuerza. Este estudio, aunque fastidioso y algo crudo, permitió ciertas deduc-O ciones respecto al poder de varios lotes, de manera que se pudo decir, por ejemplo, que "El lote A es cuatro N
veces menos potente que el lote B ".

Tres métodos fueron comprobados: intramuscular ${ }^{N}$ continuo, intramuscular intermitente, e intravenosoN intermitente, gota a gota durante ocho horas. $\mathrm{El}^{\mathrm{\omega}}$ último método parece el mejor. Hay que seguir elo procedimiento de un intervalo de 4 días o más, para quee se pueda llegar al equilibrio de base, con dosis de $10 \mathrm{mg}$., norma Armour. Un período de entrenamiento previoo con varios tests es aconsejable, así como la comprobación ? de los resultados con los obtenidos con inyecciones de $\underset{T}{T}$ suero fisiológico. 